\title{
Efek Usia dan Tingkat Pendidikan terhadap Kinerja Tenaga Bantu Penyuluh Pertanian
}

\section{Effects of Ange and Level of Education on the Performance of Agricultural Extension Assistants}

\author{
Danang Sudarso Widya Prakoso Joyo Widakdo*), Abdul Holik, Lutfi Nur Iska
}

Program Studi Agribisnis, Politeknik Negeri Banyuwangi, Banyuwangi 68461, Indonesia

*)E-mail korespondensi: danang.sudarso@ poliwangi.ac.id

Diterima: 10 Juli 2020 | Disetujui: 16 Maret 2021 | Publikasi Online: 22 Maret 2021

\begin{abstract}
The purpose of this study was to determine the effect of age and level of education on the performance of agricultural extension assistants, either simultaneously or partially. This research is an explanatory study with a quantitative approach. The sample of the research was the Agricultural Extension Assistants in Banyuwangi Regency. The sampling technique was a total sampling of 40 respondents. The main data of this research are primary data obtained by data collection techniques using a questionnaire. The analytical tool used multiple linear regression to determine the effect simultaneously and partially. The results showed that age and education level had a positive and significant effect on the performance of agricultural extension assistants, either simultaneously or partially.
\end{abstract}

Kata kunci: Age, level of education, performance of the instructor

\section{ABSTRAK}

Tujuan penelitian ini adalah mengetahui pengaruh usia dan tingkat pendidikan terhadap kinerja tenaga bantu penyuluh pertanian baik secara simultan maupun parsial. Penelitian ini merupakan penelitian eksplanatori dengan pendekatan kuantitatif. Sampel penelitian adalah tenaga bantu penyuluh pertanian di Kabupaten Banyuwangi dengan teknik pengambilan sampel adalah total sampling yang berjumlah 40 responden. Data utama penelitian adalah data primer yang diperoleh dengan teknik pengumpulan data menggunakan kuesioner. Alat analisis yang digunakan regresi linier berganda untuk mengetahui pengaruh secara simultan dan parsial. Hasil penelitian menunjukkan bahwa usia dan tingkat pendidikan berpengaruh positif dan signifikan terhadap kinerja tenaga bantu penyuluh pertanian baik secara simultan maupun parsial.

Kata kunci: Kinerja penyuluh, tingkat pendidikan, usia 


\section{PENDAHULUAN}

Sumber Daya Manusia (SDM) merupakan suatu proses menangani berbagai masalah pada ruang lingkup karyawan, pegawai, buruh, manajer dan tenaga kerja lainnya untuk dapat menunjang aktivitas organisasi atau perusahaan demi mencapai tujuan yang telah ditentukan. Manajer harus menjamin bahwa perusahaan atau suatu organisasi memiliki tenaga kerja yang tepat di tempat yang tepat, dan pada saat yang tepat, serta memiliki kemampuan untuk menyelesaikan tugas-tugas yang akan menolong perusahaan tersebut mencapai sarana-sarana secara keseluruhan secara efektif dan efisien (Masram dan Mu'ah, 2017). Menurut Montolalu et al. (2016), sumber daya manusia merupakan salah satu faktor penting dalam suatu organisasi atau instansi, sumber daya manusia yang baik untuk mendukung tercapainya tujuan dari organisasi. Pengembangan pertanian ke depan diharapkan dapat memberikan kontribusi yang lebih besar dalam rangka mengurangi kesenjangan dan memperluas lapangan pekerjaan, serta mampu memanfaatkan peluang ekonomi yang terjadi sebagai dampak dari globalisasi, oleh karena itu diperlukan sumber daya manusia yang berkualitas dan memiliki jiwa kompeten yang tinggi. Usia tenaga kerja dalam penyuluh adalah salah satu upaya untuk meningkatkan sumber daya manusia di bidang pertanian, agar dapat berjalan secara efektif dan efisien.

Usia adalah waktu ketika seseorang terhitung mulai saat dilahirkan sampai dengan berulang tahun, semakin cukup umur, tingkat kematangan, dan kekuatan seseorang akan lebih matang dalam berfikir dan bekerja. Usia dilihat dari segi kepercayaan masyarakat, seorang yang lebih dewasa lebih dipercaya dari orang yang belum tinggi kedewasaannya, hal ini sebagai pengalaman dan kematangan jiwa (Lasut et al., 2017). Usia dan tingkat pendidikan merupakan faktor yang berkaitan langsung dengan kinerja khususnya pada profesi penyuluh, dimana usia produktif mampu meningkatkan kinerja tenaga harian lepas tenaga bantu penyuluh pertanian. Usia produktif merupakan orang yang masih dapat bekerja dengan baik untuk mencapai target penyuluhan dengan optimal dan mampu menyelesaikan permasalahan yang dialami para petani. Hal ini didukung oleh pendapat Warr (1994) yang menyatakan bahwa usia merupakan penentu kinerja individu, yaitu kinerja individu secara bertahap akan meningkat atau menurun seiring bertambahnya usia tergantung pada pekerjaan mereka.

Beberapa penelitian menemukan bahwa usia mempengaruhi dalam menghasilkan kinerja yang lebih baik dan hasilnya menunjukkan bahwa belajar bahasa Inggris pada usia dini merupakan hal yang penting (Elsadig dan Khalifa, 2012). Penelitian lain oleh Fauzilah et al. (2012) menyimpulkan bahwa tidak ada perbedaan yang signifikan antara kinerja penjualan dan karakteristik demografi pelaku usaha seperti usia. Beberapa penelitian menunjukkan bahwa pedagang, muda dan tua masing-masing dapat berperan dalam menentukan keberhasilan suatu bisnis berdasarkan penjualan. Misalnya studi tentang Heck et al. (1995) menyimpulkan bahwa semakin tinggi pemilik usaha maka kinerja yang lebih baik. Penelitian lain oleh Orser dan Foster (1992) menghasilkan hasil yang sama bahwa pemilik bisnis berusia 40 tahun ke atas memiliki kesempatan untuk menghasilkan lebih banyak daripada mereka yang berusia kurang dari 40 tahun. Studi yang berbeda meneliti tentang perbedaan tingkat kinerja para pekerja pabrik Gula Chittoor di kota Chittoor, India Selatan menemukan bahwa bagaimana faktor usia dan jenis kelamin mempengaruhi tingkat kinerja pekerja di perusahaan. Setelah dipelajari, ditemukan bahwa dua variabel yang diteliti memiliki pengaruh langsung terhadap kinerja pekerja pada tingkat yang berbeda-beda. Pekerja dalam rentang usia menengah, memilki kinerja lebih baik dibandingkan dengan pekerja dengan rentang usia yang lain. Jenis kelamin juga ternyata berpengaruh terhadap kinerja dan pekerja perempuan relatif lebih produktif (Kotur and Anbazhagan, 2014).

Pendidikan merupakan proses pemberdayaan potensi dan kompetensi individu untuk menjadi manusia yang berkualitas dan bermanfaat selama hidupnya. Pendidikan mampu mengangkat kehidupan manusia ke dalam kelas sosial yang lebih tinggi, pendidikan dapat dipergunakan untuk membantu penduduk dalam meningkatkan taraf hidupnya ke tingkat yang lebih tinggi melalui usaha mereka sendiri. Pendidikan tidak terlepas dari perubahan sosial di dalam masyarakat demokratis, hal ini berarti bahwa pendidikan dilahirkan sebagai bagian dari kehidupan sosial dan oleh sebab itu, kehidupan sosial tersebut merupakan suatu realitas yang dinamis, maka pendidikan harus selalu bergerak mengikuti perkembangan zaman (Asmirawanti et al., 2016). Penelitian lain menemukan bahwa penunjang kinerja diantaranya adalah usia dan tingkat pendidikan (Harahap, 2019). Hasudungan (2017) menemukan bahwa umur dan tingkat pendidikan secara parsial tidak berpengaruh signifikan terhadap kinerja, tetapi secara simultan berpengaruh terhadap kinerja. 
Penyuluh pertanian berperan penting dalam pertanian untuk mewujudkan kegiatan yang dijalankan petani dengan pengetahuan dan teknologi yang berkembang, sehingga dapat dipraktikkan oleh petani untuk meningkatkan produktivitas pertanian. Keberhasilan kegiatan penyuluhan juga ditentukan dengan adanya dukungan dari tenaga kerja penyuluh dalam melaksanakan penyuluhan sesuai kebutuhan petani. Kegiatan penyuluhan pertanian diharapkan memiliki kemampuan pembinaan para petani dalam memperbaiki hidupnya, sehingga mampu meningkatkan peran sertanya dalam pembangunan pertanian agar tercipta pertanian yang maju dan efisien. Selain itu melalui kegiatan penyuluhan dapat meningkatkan perkembangan kelompok tani baik dari segi kualitas maupun kuantitas, adanya hubungan baik dengan instansi terkait, peningkatan produksi, dan akhirnya peningkatan ekonomi bagi petani. Permasalahan pembangunan pertanian meliputi: lahan pertanian, infrastruktur, benih, kelembagaan, permodalan dan sumber daya manusia (SDM). Permasalahan dalam hal SDM adalah keterbatasan tenaga penyuluh pertanian baik dari segi kuantitas maupun kualitasnya. Arah kebijakan pembangunan pertanian tahun 2015-2019 adalah untuk mengatasi permasalahan SDM dengan meningkatkan kuantitas dan kualitas kinerja penyuluh pertanian. Data usia, tingkat pendidikan dan presentase kerja tenaga harian lepas tenaga bantu penyuluh pertanian Kabupaten Banyuwangi tahun 2017-2019 dapat dilihat pada Tabel 1.

Tabel 1. Usia, tingkat pendidikan dan nilai prestasi kerja Tenaga Harian Lepas Tenaga Bantu Penyuluh Pertanian (THL TBPP) di Kabupaten Banyuwangi tahun 2017-2019

\begin{tabular}{cccclc}
\hline Usia & \multicolumn{2}{c}{ Tingkat Pendidikan } & \multicolumn{2}{c}{ Nilai Prestasi Kerja (NPK) } \\
\hline Kategori & Persen & Jenjang & Persen & \multicolumn{1}{c}{ Kategori } & Persen \\
\hline $35-40$ & 15 & SMK (Pertanian) & 22 & Cukup & 10 \\
$41-45$ & 32 & D III & 5 & Baik & 87 \\
$46-50$ & 18 & S 1 & 73 & Sangat baik & 3 \\
$51-55$ & 30 & & & & \\
$56-60$ & 5 & & & & \\
\hline
\end{tabular}

Sumber : Dinas Pertanian dan Ketahanan Pangan Provinsi Jawa Timur (2019)

Usia tenaga harian lepas tenaga bantu penyuluh pertanian pada tahun 2017-2019 mulai dari 35-58 tahun. Berdasarkan rentang usia ini sebagian besar berada pada usia produktif yaitu usia 35-40 tahun sebesar $15 \%$, usia 41-45 sebesar 32\%, usia 46-50 tahun sebesar 18\% dan usia 51-55 tahun sebesar 30\%. Berdasarkan data di atas jumlah usia penyuluh tenaga harian lepas tenaga bantu penyuluh pertanian terbesar pada 41-45 tahun (32\%). Usia tenaga harian lepas tenaga bantu penyuluh pertanian ini bervariasi, sehingga dapat berpengaruh terhadap kinerja. Usia dan kinerja adalah salah satu hal yang saling berhubungan yakni kinerja menurun dengan bertambahnya usia. Keahlian seseorang, kecepatan, tenaga, akan menyusut dari waktu ke waktu, hal ini menambah kejenuhan bekerja, sehingga mempengaruhi menurunnya produktivitas.

Tingkat pendidikan tenaga harian lepas tenaga bantu penyuluh pertanian di Kabupaten Banyuwangi pada tahun 2017-2019 dengan kategori tingkatan yang berbeda-beda di antarannya SMK, D-III, dan S1. Tingkat pendidikan SMK khususnya SMK pertanian sebesar 22\%, jenjang D-III sebesar 5\% dan jenjang S-1 sebesar 73\%. Berdasarkan data di atas tingkat pendidikan penyuluh THL TBPP terbesar adalah Sarjana (73\%).

Evaluasi dilakukan untuk mengetahui kinerja selama satu tahun, jika kinerja baik maka akan diteruskan kontrak kerja selama satu tahun ke depan. Evaluasi dilakukan bertujuan untuk meningkatkan kinerja tenaga harian lepas tenaga bantu penyuluh pertanian. Data di atas menunjukkan NPK (Nilai Prestasi Kerja) dapat dikategorikan sangat baik, baik dan cukup. Kategori sangat baik sebesar 3\%, kategori cukup sebesar $10 \%$. Kesimpulan yang dapat diambil dari data evaluasi kinerja penyuluh pada tahun 2017-2019 yaitu rata-rata jumlah prestasi kerja tenaga harian lepas tenaga bantu penyuluh pertanian baik $(87 \%)$.

Berdasarkan beberapa uraian di atas, penelitian tertarik untuk mengkaji lebih dalam tentang pengaruh usia dan tingkat pendidikan terhadap kinerja penyuluh di Kabupaten Banyuwangi khususnya pada tenaga harian lepas tenaga bantu penyuluh pertanian Kabupaten Banyuwangi baik secara simultan (bersama-sama) maupun secara parsial (individu). 


\section{METODE PENELITIAN}

Penelitian ini merupakan penelitian eksplanatori yang bertujuan mengetahui hubungan-hubungan antar satu variabel dengan variabel lainnya atau bagaimana suatu variabel memengaruhi variabel lainnya (Umar, 2013). Pendekatan dalam penelitian ini adalah kuantitatif, datanya berupa angka-angka dan penelitian ini bermaksud menguji hipotesis tertentu (Tuckman, 1999). Jenis penelitian adalah survey, yakni cross sectional survey (Borg dan Gall, 2003). Penelitian dilakukan di Dinas Pertanian Kabupaten Banyuwangi, Jl. Jaksa Agung Suprapto No. 80, Penganjuran, Mojopanggung, Giri, Kabupaten Banyuwangi, Jawa Timur 68425. Lokasi ini dipilih karena merupakan salah satu pusat penyuluh di Kabupaten Banyuwangi yang memungkinkan untuk penelitian tentang usia, tingkat pendidikan dan kinerja.

Populasi penelitian adalah Tenaga Harian Lepas Tenaga Bantu Penyuluh Pertanian (THL TBPP) di Kabupaten Banyuwangi. Adapun sampel penelitian berjumlah 40 responden dengan teknik pengambilan sampel menggunakan total sampling. Pengumpulan data bersumber dari data primer dan data sekunder. Data primer yang diperoleh dengan cara observasi yaitu melakukan pengamatan dan mengumpulkan data secara langsung kegiatan yang telah dan sedang dilakukan di lokasi penelitian BPP dan didukung dengan penyebaran kuesioner (seperangkat pernyataan tertutup) yang dilaksanakan pada bulan Maret 2020. Kuesioner merupakan teknik pengumpulan data yang dilakukan dengan cara memberi seperangkat pertanyaan atau pernyataan tertulis kepada responden untuk dijawab. Kuesioner dapat berupa pertanyaan atau pernyataan tertutup atau terbuka dapat diberikan kepada responden secara langsung atau dikirim melalui pos atau internet (Sugiyono, 2016).

Alat analisis yang digunakan adalah regresi linier berganda. Hal ini dilakukan untuk melihat pengaruh usia dan tingkat pendidikan terhadap kinerja tenaga bantu penyuluh pertanian. Sebelum data dianalisis lebih lanjut, dilaksanakan dulu uji kualitas data (uji validitas dan uji reliabilitas) serta uji asumsi klasik (uji normalitas, uji multikolineritas dan uji heteroskedastisitas). Adapun hasil uji kualitas data dan uji asumsi klasik sebagai berikut:

Tabel 2. Hasil Uji Validitas dan Reliabilitas

\begin{tabular}{cccccccc}
\hline \multirow{2}{*}{ Butir } & \multicolumn{6}{c}{ Variabel } & Nilai \\
\cline { 2 - 6 } & \multicolumn{2}{c}{ Usia } & \multicolumn{2}{c}{ Tingkat Pendidikan } & \multicolumn{2}{c}{ Kinerja } & Kritikal \\
\cline { 2 - 6 } & r-hitung & keterangan & r-hitung & keterangan & r-hitung & keterangan & r-tabel \\
\hline 1 & 0,683 & Valid & 0,653 & Valid & 0,679 & Valid & \\
2 & 0,562 & Valid & 0,770 & Valid & 0,755 & Valid & \\
3 & 0,542 & Valid & 0,810 & Valid & 0,604 & Valid & 0,312 \\
4 & 0,579 & Valid & 0,874 & Valid & 0,646 & Valid & \\
5 & 0,783 & Valid & 0,800 & Valid & 0,691 & Valid & \\
6 & 0,706 & Valid & 0,874 & Valid & 0,724 & Valid & \\
\hline \multicolumn{7}{c}{ Cronbach's Alpha } \\
\end{tabular}

Sumber: Data Primer Diolah, 2019.

Uji validitas dilakukan dengan membandingkan nilai r-hitung dengan r-tabel, untuk degree of freedom $(\mathrm{df})=\mathrm{n}-2, \mathrm{n}$ adalah jumlah sampel. Jumlah sampel $(\mathrm{n})=40$ dan besarnya df dapat dihitung $40-2=38$ dengan $\mathrm{df}=38$ dan alpha $=0,05$ didapat $r$-tabel dari tabel $r$-product moment $=0,312$. Jika r-hitung $>r$ tabel maka butir pernyataan atau indikator tersebut dinyatakan valid (Ghozali, 2016). Hasil uji validitas dapat disimpulkan bahwa hasil analisis yang telah dilakukan dari keseluruhan item yang digunakan dikatakan valid, karena pernyataan dapat dilihat dari r-hitung lebih besar dari r-tabel, maka butir pernyataan pada variabel usia, tingkat pendidikan dan kinerja dinyatakan valid.

Hasil uji reliabilitas pada masing-masing variabel yaitu Usia (X1) dengan nilai Cronbach's Alpha 0,708, tingkat pendidikan (X2) dengan nilai Cronbach's Alpha 0,884 dan Kinerja (Y) dengan nilai Cronbach's Alpha 0,766. Noor (2015), menyatakan bahwa apabila koefisien reliabilitas yang diperoleh lebih besar dari 0,6 maka kuesioner yang disebarkan dapat diandalkan untuk disajikan sebagai alat ukur pada penelitian. Hal ini menunjukkan semua variabel yang menjadi pernyataan dalam kuesioner berapa kali dinyatakan kepada responden pada penelitian pada waktu dan tempat yang berbeda menghasilkan ukur yang sama, karena nilai Cronbach's Alpha $>0,60$ sehingga dapat dikatakan reliabel. 
Tabel 3. Hasil Uji Asumsi Klasik

\begin{tabular}{lcccccc}
\hline \multirow{2}{*}{ Variabel } & \multicolumn{2}{c}{ Uji Normalitas } & \multicolumn{2}{c}{ Uji Multikolinieritas } & \multicolumn{2}{c}{ Uji Heteroskedastisitas } \\
\cline { 2 - 7 } & Sign. & Keterangan & VIF & Keterangan & Sign. & Keterangan \\
\hline Usia & 0,880 & Normal & 1,095 & Non-multi & 0,245 & Non-hetero \\
Tingkat pendidikan & 0,111 & Normal & 1,095 & Non-multi & 0,621 & Non-hetero \\
Kinerja & 0,128 & Normal & & & & \\
\hline
\end{tabular}

Sumber: Data Primer Diolah, 2019

Ghozali (2016), menyatakan uji normalitas bertujuan untuk menguji apakah dalam model regresi variabel pengganggu atau residual memiliki distribusi normal. Pendekatan normalitas secara statistik adalah dengan menggunakan uji Kolmogorov-Smirnov. Uji Kolmogorov-Smirnov merupakan uji normalitas yang umum digunakan karena dinilai lebih sederhana dan tidak menimbulkan perbedaan persepsi. Uji Kolmogorov-Smirnov dilakukan dengan nilai signifikan 0,05, untuk lebih sederhana pengujian ini dapat dilakukan dengan melihat profitabilitas dari Kolmogorov-Smirnov Z statistik. Jika profitabilitas $\mathrm{Z}$ statistik lebih kecil dari 0,05 maka nilai residual dalam satu regresi tidak terdistribusi secara normal (Ghozali, 2016). Hasil uji normalitas menunjukkan distribusi data pada variabel usia (X1) sebesar 0,88>0,05, tingkat pendidikan (X2) sebesar 0,111>0,05 dan kinerja penyuluh (Y) sebesar $0,128>0,05$, artinya data memiliki distribusi normal karena sesuai dengan asumsi normalitas data $>$ 0,05 .

Model regresi yang baik seharusnya tidak terjadi korelasi antar variabel independen. Uji multikolinieritas dapat diketahui dengan nilai tolerance > 0,10 dan nilai Variance Inflation Factor (VIF) $<10$, maka tidak terjadi multikolinieritas pada model regresi. Hasil uji multikolinieritas menunjukkan bahwa nilai tolerance usia (X1) dan tingkat pendidikan (X2) sebesar 0,913 > 0,10 dan nilai Variance Inflation Factor (VIF) sebesar 1,095 < 10. Jika nilai Tolerance > 0,10 dan nilai Variance Inflation Factor (VIF) < 10 maka tidak terjadi multikolineritas antara variabel independen. Maka data variabel usia (X1) dan tingkat pendidikan (X2) tidak mengalami multikolinieritas antar variabel independen.

Model regresi yang baik yaitu tidak terjadi heteroskedastisitas, jika variabel independen mempunyai nilai signifikansi $>0,05$ (Ghozali 2016). Titik-titik yang menyebar secara acak dan tersebar baik di atas maupun di bawah angka 0 pada sumbu Y dan tidak membentuk pola tertentu. Hal ini dapat disimpulkan bahwa tidak terjadi heteroskedastisitas pada model regresi, sehigga model regresi layak dipakai untuk usia dan tingkat pendidikan terhadap kinerja penyuluh THL TBPP (Pusat) di Kabupaten Banyuwangi. Hasil uji heteroskedastisitas menunjukkan bahwa kedua model yaitu usia (X1) dan tingkat pendidikan (X2) memiliki nilai signifikansi masing-masing sebesar 0,245>0,05 dan 0,621 >0,05, artinya usia (X1) dan tingkat pendidikan (X2) memenuhi syarat dari uji heteroskedastisitas karena nilai signifikansi lebih dari 0,05, maka dapat disimpulkan tidak terjadi heteroskedastisitas pada kedua model tersebut, sehingga layak digunakan untuk penelitian.

\section{HASIL DAN PEMBAHASAN}

Uji regresi linier berganda digunakan untuk mengukur kekuatan hubungan antara dua variabel independen atau lebih terhadap variabel dependen, yaitu usia dan tingkat pendidikan terhadap kinerja penyuluh. Hasil regresi linier berganda menggunakan aplikasi SPSS disajikan pada Tabel 4.

Tabel 4. Rekapitulasi Hasil Uji Regresi Linier Berganda

\begin{tabular}{|c|c|c|c|c|c|}
\hline \multirow{2}{*}{ No. } & \multirow[b]{2}{*}{ Variabel Bebas } & \multirow[b]{2}{*}{ Koefisien regresi } & \multicolumn{2}{|c|}{ Penyajian hipotesis } & \multirow{2}{*}{$\underset{\text { (p-value }}{\text { Sign. }}$} \\
\hline & & & t-hitung & t-tabel & \\
\hline 1 & Usia $\left(X_{1}\right)$ & 0,261 & 2,231 & 2,024 & 0,032 \\
\hline 2 & Tingkat pendidikan $\left(\mathrm{X}_{2}\right)$ & 0,406 & 3,911 & & 0,000 \\
\hline \multicolumn{2}{|c|}{ Konstanta } & 6,784 & & & \\
\hline \multicolumn{2}{|c|}{$\mathrm{R}^{2}$} & 0,429 & & & \\
\hline \multicolumn{2}{|c|}{ F-hitung } & 13,922 & & & \\
\hline \multicolumn{2}{|c|}{ F-tabel $(5 \%)$} & 3,240 & & & \\
\hline \multicolumn{2}{|c|}{ Signifikansi } & 0,000 & & & \\
\hline
\end{tabular}

Sumber: Data primer (diolah), 2019. 
Pengujian secara bersama-sama pengaruh usia dan tingkat pendidikan terhadap kinerja tenaga bantu penyuluh pertanian dengan uji F diperoleh nilai F-hitung sebesar 13,922 ( $p$-value $=0,000)$ dan nilai Ftabel sebesar 3,240. Nilai F-hitung lebih besar dari nilai F-tabel $(13,922>3,240)$, yang berarti bahwa variabel usia dan tingkat pendidikan secara bersama-sama (simultan) berpengaruh signifikan terhadap kinerja tenaga bantu penyuluh pertanian. Adapun besarnya pengaruh dapat diketahui dari nilai koefisien determinasi $\left(\mathrm{R}^{2}\right)$.

Koefisien determinasi $\left(\mathrm{R}^{2}\right)$ pada dasarnya mengukur kemampuan model regresi dalam menjelaskan variabel dependen (kinerja) dengan nilai antara nol sampai dengan satu. Nilai $R^{2}$ yang kecil berarti kemampuan variabel-variabel independen dalam menjelaskan variasi variabel dependen sangat terbatas. Nilai yang mendekati satu berarti variabel-variabel independen memberikan hampir semua informasi yang dibutuhkan untuk memprediksi variasi variabel dependen (Levesque, 2007). Hasil penelitian ini menjelaskan bahwa besarnya nilai $\mathrm{R}^{2}$ Square adalah 0,429 , jika variabel-variabel independen dapat dikatakan semakin kuat model tersebut dalam menerangkan pengaruh variabel independen yaitu usia dan tingkat pendidikan terhadap variabel dependen yaitu kinerja penyuluh (Ghozali, 2016), maka hal ini berarti $42,9 \%$ kinerja penyuluh dipengaruhi oleh usia dan tingkat pendidikan, sedangkan sisanya 57,1\% kinerja penyuluh dapat dipengaruhi oleh variabel lain yang tidak dijelaskan dalam penelitian.

Pengujian pengaruh usia terhadap kinerja tenaga bantu penyuluh pertanian diperoleh koefisien regresi sebesar 0,261 yang menunjukkan bahwa adanya peningkatan usia akan menyebabkan peningkatan kinerja pegawai dengan asumsi variabel bebas lainnya konstan. Pengujian pengaruh usia terhadap kinerja pegawai diperoleh nilai t-hitung sebesar 2,231 ( $p$-value $=0,032)$ dan nilai t-tabel sebesar 2,024. Nilai t-hitung lebih besar dari nilai t-tabel $(2,231>2,024)$, yang berarti bahwa variabel usia berpengaruh positif dan signifikan terhadap kinerja tenaga bantu penyuluh pertanian.

Penyuluh THL TBPP, memiliki anggota rata-rata usia antara 35-60, dengan mayoritas 41-45 tahun, yang memiliki latar belakang tingkat pendidikan yang berbeda-beda. Usia yang semakin tua bukan berarti seseorang memiliki ilmu atau pengetahuan yang lebih baik dibandingkan dengan anggota yang usianya lebih muda karena usia yang lebih muda cenderung memiliki daya tangkap dan ingatan yang lebih baik terhadap informasi yang baru dibandingkan dengan usia yang lebih tua. Usia juga mempengaruhi tingkat kestabilan emosi seseorang dalam menghadapi setiap permasalahan. Usia yang lebih tua cenderung memiliki tingkat kestabilan emosi yang lebih baik dibandingkan dengan usia yang muda. Umur berkaitan erat dengan tingkat kedewasaan atau maturitas pegawai. Kedewasaan adalah tingkat kemampuan teknis dalam melakukan tugas maupun kedewasaan psikologis, semakin bertambah lanjut usia seseorang semakin meningkat pula kedewasaan seseorang, demikian juga psikologisnya akan menunjukkan kematangan jiwa. Robbins and Judge (2008) mengungkapkan bahwa jika penelitian memisahkan antara profesional dan non profesional, maka akan didapatkan bahwa tingkat kinerja cenderung meningkat pada profesional dengan bertambahnya usia, sedangkan pada nonprofesional kinerja menurun seiring dengan pertambahan usia.

Pengaruh tingkat pendidikan terhadap tenaga bantu penyuluh pertanian diperoleh koefisien regresi sebesar 0,406 yang menunjukkan bahwa semakin tingkat pendidikan tenaga bantu penyuluh pertanian akan menyebabkan peningkatan kinerja dengan asumsi variabel bebas lainnya konstan. Pengujian pengaruh tingkat pendidikan terhadap kinerja tenaga bantu penyuluh pertanian diperoleh nilai t-hitung sebesar 3,911 ( $p$-value $=0,000)$. Nilai t-hitung lebih besar dari nilai t-tabel $(3,911>2,024)$, yang berarti bahwa variabel tingkat pendidikan berpengaruh positif dan signifikan terhadap kinerja tenaga bantu penyuluh pertanian.

Penyuluh THL TBPP di Kabupaten Banyuwangi memilik latar belakang pendidikan yang berbeda-beda, mayoritas tingkat pendidikannya yaitu sarjana. Latar pendidikan penyuluh juga tidak hanya dari pertanian, tapi keahlian dalam bidang pertanian harus dimiliki oleh seorang penyuluh untuk meningkatkan kesejahteraan petani. Pelatihan yang dilakukan dapat menambah pengetahuan dan pengalaman anggota penyuluh THL TBPP. Pelatihan yang dilakukan 1-3 kali dalam setahun, sehingga dapat menunjang kualitas penyuluh THL TBPP dalam menyampaikan informasi dan ilmu kepada petani. Penelitian ini menemukan bahwa tingkat pendidikan berpengaruh positif signifikan terhadap kinerja tenaga bantu penyuluh pertanian. Menurut Lepak dan Snell (1999), pendidikan mempengaruhi produktivitas dapat memengaruhi dukungan korporat untuk subsidi pemerintah untuk pendidikan. Prestasi pendidikan individu tidak hanya bagian dari sumber daya manusia perusahaan tetapi juga merupakan bagian dari aset inti masyarakat. Pada beberapa kasus, subsidi untuk pendidikan sebagian besar didasarkan pada asumsi bahwa investasi pemerintah dalam modal manusia akan memperkuat 
ekonomi secara keseluruhan dengan meningkatkan produktivitas karyawan (Lanzi, 2007; Trusty dan Niles, 2004). Bila pendidikan tidak menghasilkan modal manusia yang proporsional dengan pengeluaran, organisasi mungkin menentang kenaikan pajak untuk pendidikan, pindah ke tempat lain dengan sistem pendidikan yang lebih baik, atau mengembangkan program pendidikan internal mereka sendiri untuk menggantikan yang didanai publik (Vinod dan Kaushik, 2007). Secara keseluruhan penelitian ini juga memperkuat penelitian Chiliya and Lombard (2012) yang menemukan bahwa tingkat pendidikan, umur pemilik dan lamanya usaha mempunyai pengaruh yang signifikan terhadap profitabilitas usaha, yang menunjukkan kinerja yang baik dalam sebuah perusahaan ataupun lembaga.

\section{KESIMPULAN}

Hasil pengujian menunjukkan bahwa variabel usia dan tingkat pendidikan secara bersama-sama (simultan) maupun individual (parsial) berpengaruh terhadap kinerja penyuluh, khususnya tenaga harian lepas tenaga bantu penyuluh pertanian di Kabupaten Banyuwangi. Hal ini menandakan apabila penyuluh tenaga harian lepas tenaga bantu penyuluh pertanian mampu menyelesaikan tugas yang diberikan oleh atasan, meningkatkan keterampilan dan meningkatkan tanggung jawab penyuluh.

Pihak pengambil keputusan hendaknya tetap menjaga agar penyuluh mampu meningkatkan kinerja dengan cepat sesuai waktu yang ditentukan, mampu menjaga kestabilan emosi serta mampu meningkatkan ketelitian dalam bekerja, sehingga hasil kinerja juga akan meningkat.

\section{UCAPAN TERIMA KASIH}

Penulis mengucapkan terimakasih kepada Politeknik Negeri Banyuwangi yang telah membiayai penelitian ini pada tahun 2020 .

\section{DAFTAR PUSTAKA}

Asmirawanti, Sulfasyah dan J. Arifin. 2016. Komersialisasi Pendidikan. Jurnal Equilibrum. 4(1): 174183.

Borg, W.R. dan M.D. Gall. 2003. Educational Research: An Introduction ( $7^{\text {th }}$ ed.). New York: Longman, Inc.

Chiliya, N. and M.R. Lombard. 2012. Impact of Level of Education and Experience on Profitability of Small Grocery Shops in South Africa. International Journal Business Management and Economics Research. 3(1): 462-470.

Dinas Pertanian dan Ketahanan Pangan Provinsi Jawa Timur. 2019. Kabupaten Banyuwangi. http://pertanian.jatimprov.go.id/kab-banyuwangi/ diakses tanggal 8 April 2020.

Elsadig, M. dan G. Khalifa. 2012. The Effects of Age Factor on Learning English: A Case Study of Learning English in Saudi Schools, Saudi Arabia. English Language Teaching Journal. 5(1): 127139.

Fauzilah, S., N. Yaakub, M. Mohamad, M.A. Ghani and W.KW. Sulong. 2012. Demographic Characteristics Differences and Sales Performance among Night Market Traders in Malaysia. International Business Research. 5(4): 25-33.

Ghozali, I. 2016. Aplikasi Analisis Multivariate dengan Program IBM SPSS 23. Semarang: BPFE Universitas Diponegoro.

Harahap, S.S. 2019. Hubungan Usia, Tingkat Pendidikan, Kemampuan Bekerja dan Masa Bekerja terhadap Kinerja Pegawai dengan Menggunakan Metode Pearson Correlation. Jurnal Teknovasi. 6(2): $12-26$

Hasudungan, L. 2017. Pengaruh Faktor Pendidikan, Umur dan Pengalaman Kerja Terhadap Kinerja Aparatur Sipil Negara (ASN) pada Dinas Pekerjaan Umum Penata Ruang, Perumahan dan Kawasan Permukiman Kabupaten Kapuas Kalimantan Tengah. Jurnal Ilmiah Ekonomi Bisnis. 3(3): 301-310.

Heck, R., B. Rowe dan A. Owen. 1995. Home Based Employment and Family Life. Westport. Connecticut: Auburn House. 
Kotur, B.R. and S. Anbazhagan. 2014. Influence of Age and Gender on the Performance. IOSR Journal of Business and Management (IOSR-JBM). 16(5): 97-103.

Lanzi, D. 2007. Capabilities, human capital, and education. Journal of Socio-Economics. 36(1): 424435.

Lasut, E.E., V.P.K. Lengkong dan I.W.J. Ogi. 2017. Analisis Perbedaan Kinerja Pegawai Berdasarkan Gender, Usia Dan Masa Kerja (Studi Pada Dinas Pendidikan Sitaro). Jurnal Riset Ekonomi, Manajemen, Bisnis dan Akuntansi. 5(2): 2771-2780.

Lepak, D.P. dan S.A. Snell. 1999. The human resource architecture: Toward a theory of human capital allocation and development. Academy of Management Review. 24(1): 31-48.

Levesque, C. and K.W. Brown. 2007. Mindfulness as a moderator of the effect of implicit motivational self-concept on day-to-day behavioral motivation. Article in Motivation and Emotion. 3(1): 284299.

Masram dan Mu'ah. 2017. Manajemen Sumber Daya Manusia Profesional. Sidoarjo: Zifatama Publiser.

Montolalu, R., L. Kawet dan O. Nelwan. 2016. Pengaruh Kepribadian, Orientasi Kerja dan Penempatan Pegawai Terhadap Kinerja Pegawai pada Dinas Kebudayaan dan Pariwsata Provinsi Sulawesi Utara. Jurnal Riset Ekonomi, Manajemen, Bisnis dan Akuntansi. 4(1): 1318-1329.

Noor, J. 2015. Metodologi Penelitian: Skripsi, Tesis, Disertasi dan Karya Ilmiah (Edisi 1, Cetakan 5). Jakarta: Kencana.

Orser, B. dan M. Foster. 1992. Home Enterprise: Canadians and Home Based Work. Canada: The Home Based Business Project Committee.

Robbins, S.P. and T.A. Judge. 2008. Organizational Behavior: Concept, Controversies and Application. New Jersey: Prentice Hall.

Sugiyono. 2016. Metode Penelitian Kuantitatif, Kualitatif dan R\&D. Bandung: Afabeta.

Trusty, J. dan S.G. Niles. 2004. Realized potential or lost talent: High school variables and bachelor's degree completion. Career Development Quarterly. 53(1): 2-15.

Tuckman, B.W. 1999. A Tripartite Model of Motivation for Achievement: Attitude, Drive, Strategy. New York: John Wiley \& Sons Inc.

Umar, H. 2013. Metode Penelitian untuk Skripsi dan Tesis. Jakarta: Rajawali.

Vinod, H. dan S.K. Kaushik. 2007. Human capital and economic growth: Evidence from developing countries. American Economist. 51(1): 29-39.

Warr, P. 1994. Age and job performance. In J. Snel \& R. R. Cremer (eds.), Work and Aging. A European Perspective (pp. 309322). London: Taylor \& Francis. 